\title{
Understanding of the interrelationships between substance use disorders, mental health, family, community and culture
}

\author{
School of Medicine \\ Griffith university \\ Queensland
}

Wole Akosile, MBBS, MPH, FRANZCP

\section{Definition/introduction /Background}

- Culture is a fuzzy set of basic assumptions and values, orientations to life, beliefs, policies, procedures and behavioural conventions that are shared by a group of people, and that influence (but do not determine) each member's behaviour and his/her interpretations of the 'meaning' of other people's behaviour.'

\section{by Professor Helen Spencer-Oatey}

- Culture is dynamic. Leaders influence culture. Leaders are products of their society. Leadership influences culture and culture influences leaders. What are the attitudes of popular world leaders towards mental health?

- Second World war-220,000 to 269,500 individuals with schizophrenia were sterilized or killed in NAZI Germany.

- Human rights watch, Jan 2018 report that President Duterte's drug war as claimed over 12000 lives

- President Trump, "When you talk about the mental health problems, when people come back from war and combat, they see things that maybe a lot of the folks in this room have seen many times over and you're strong and can handle it, but a lot of people can't handle it. ..."

- This is a popular narrative, that it's a sign of weakness

- 2014 Stigma in Canada survey about depression revealed people are ashamed or feel they will be stigmatized if they admit to having depression.

- With stigma come labels, we love labels, "when we can label it then we can understand it"

- ...Mental illness labels are accompanied by devaluation and discrimination

\section{Stigma}

- The study by Hipes et al on the stigma of living with a mental illness in the labour market revealed significant discrimination against applicants living with a mental illness.

\section{Is Addiction a mental illness?}

- NIDA defines Substance use disorder as a chronic, relapsing brain disease that is characterized by compulsive drug seeking and use, despite harmful consequences

- Substance use disorder is a chronic complex medical illness with significant social consequences. Individuals with substance use disorder mostly have co-existing non-substance use disorder.

- Does a name, or label matter?-addicts, alcoholics, drugos, Meth Head etc, In our society it does!

- The business world spends millions in branding and creating appropriate names and labels.
- The public's view of people living with mental illness due to negative labels is associated with dangerousness and desire for social distance (Link et al 2011)

\section{Discrimination within the health system}

The NHS commissioned a report through the London school of economics lead by Professor Lord Richard Layard to investigate discrimination within the mental health system in 2012 they found;

- NHS in England was guilty of injustice in its treatment of people with mental illness

- They found that among those aged under 65 , nearly half of all ill-health was mental illness.

- six million people had depression or anxiety conditions and yet three-quarters got no treatment.

- Mental health is so central to the health of individuals and of society that it needs its own cabinet minister.

\section{Family and early development}

- Social learning is the most common way people learn

- Children and adolescents learn alcohol-related behaviours from the modelling of their parents and "important others" in their life.

- Its do as I do and not do as I say.

- The social interactions that have the greatest influence on our lives are with the people who mattered to us as we grew up.

- Early childhood stress (ELS) can predict the development of psychopathology in adults.

- ELS triggers, aggravates, maintains, and increases the recurrence of psychiatric disorders.

\section{Way Forward}

- Government sponsored relationship counselling when two adults have chosen to be partnered or decide to have children.

- Government sponsored parenting support in at risk families.

- Good pre-natal screening for mental health issues and

SUDS with provision of support (hicks et al).

- Targeted public health campaigns educating young people on the need to delay the first drink, joint, smoke or sniff...

- Reviewing school curriculum with implementation of Teaching and modelling effective coping skills from primary school (Collins et al)

- Tax benefits to companies who hire people living with a mental illness or suds i.e if $5 \%$ of work staff meet this criteria, certain tax breaks apply.

- Investment in evidence based rehabilitation services.

- Health workers--Stop the negative labels, speak about SUDS as a medical disorder with social consequences and remember all medical disorders have social consequences!!! Conclusion

Culture and mental health is not just about culture bound syndromes but rather attitudes towards mental illness changing for the better.

Copyright @ Wole Akosile ) 